\title{
From Pipes to Scopes: The Flow Architecture of Financial Markets
}

\author{
Karin Knorr Cetina
}

\begin{abstract}
This article introduces a distinction between two types of markets and market coordination: those based on social networks and those based on a flow architecture. Flow architectures involve potentially global "scopic" reflex systems (GRSs) that project market reality while at the same time carrying it forward and allowing it to flow. The argument is that some financial markets have undergone a transition from a pre-reflexive network market to a reflexively coordinated flow market manifest in the different organization of trading floors, changes in trading patterns and the emergence of a moving market that gets transferred from time-zone to time-zone with the sun. To understand these markets, temporal concepts are needed in addition to the social structural (relational) concepts with which we commonly work. Networks emerge from this analysis as historically specific, relationship-based forms of market coordination which in some markets are in the process of being replaced by more reflexive temporal forms of coordination.
\end{abstract}

Keywords: financial markets, foreign exchange market, networks, global reflex systems, coordination, flow, market architecture

\section{Theoretical Considerations}

Recently, economic sociologists have tended to view markets as embedded in social relations and social networks, the structures they see as defining markets and framing economic action (e.g. White 1981; 1993; 2002; Baker 1981; 1984; Baker/Faulkner/Fisher 1998; Granovetter 1985; Swedberg/Granovetter 1992; Swedberg 1994; 1997; Burt 1983; 1992; DiMaggio/Louch 1998; Uzzi 1997; 1999; Podolny 2001). ${ }^{1}$ This article draws a distinction between two types of markets: those based on a network architecture where social relationships carry much of the burden of specifying market behavior and of explaining some market outcomes, and markets that have become disembedded and decoupled from networks and exhibit what I shall call a flow architecture. ${ }^{2}$ As illustrated elsewhere (Knorr Cetina/Bruegger 2002a; 2002b), flow architectures are "microstructured" rather than simply network/relationally-structured. They are more richly structured than the relational vocabulary allows for, and display patterns of coordination and behavior that are global in scope and microlevel in character. As Fligstein notes (1996: 657), networks are sparse social structures, and it is difficult to see how they can incorporate the patterns of intense conversational interaction, the knowledge flows, and the temporal features observed in some areas of practice. Though flow architectures may include networks, these networks are not the salient structuring principle of a global microstructure. Flow architectures, I shall argue in this paper, also involve global "scopic" systems that project market reality while at the same time carrying it forward and allowing it "to flow". The term "-scope", derived from the Greek "sco-

I I am heavily indebted to the managers, traders, salespersons, and analysts whose activities I studied together with Urs Bruegger, my co-author on other papers, and who so generously shared with us the information we collected. Research for this paper is supported by a grant from the Deutsche Forschungsgemeinschaft.

2 For a more general use of the term "architecture" in relation to market institutions approached from the angle of a theory of fields see Fligstein (2001). 
pein", to see, when combined with a qualifying notion means an instrument etc. for seeing or observing, as in "periscope". Social scientists tend to think in terms of mechanisms of coordination, which is what the network notion stands for; a network is an arrangement of nodes tied together by relationships which serve as conduits of communication, resources, and other coordinating instances that hold the arrangement together by passing between the nodes. Cooperations, strategic alliances, exchange, emotional bonds, kinship ties, "personal relations", and forms of grouping and entrenchment can all be seen to work through ties and to instantiate sociality in networks of relationships. But we should also think in terms of reflexive mechanisms of observation and projection, which the relational vocabulary does not capture. Like an array of crystals acting as lenses that collect light, focussing it on one point, such mechanisms collect and focus activities, interests, and events on one surface, from whence the result may then be projected again in different directions. When such a mechanism is in place, coordination and activities respond to the projected reality to which participants become oriented. The system acts as a centering and mediating device through which things pass and from which they flow forward. An ordinary observer who monitors events is an instrument for seeing. When such an ordinary observer constructs a textual or visual rendering of the observed and televises it to an audience, the audience may start to react to the features of the reflected, represented reality rather than to the embodied, pre-reflexive occurrences. In the financial markets studied the reflexive mechanism and "projection plane" is the computer screen; with the screen come software and hardware systems that provide a vast range of observation, presentation, and interaction capabilities sustained by information and service provider firms. Given these affordances, the pre-reflexive reality is cut off and replaced; some of the mechanisms that we take for granted in a lifeworld, for example its performative possibilities, have been integrated into the systems, while others have been replaced by specialized processes that feed the screen. The technical systems gather up a lifeworld while simultaneously projecting it. They also "apresent" (bring near, see Schutz/Luckmann 1973) and project layers of context and horizons that are out of reach in ordinary lifeworlds - they deliver not only transnational situations but a global world spanning all major time zones. As I shall argue in section 3, they do this from trading floors located in global cities (Sassen 2001) which serve as the bridgehead centers of the flow architecture of financial markets. Raised to a level of analytic abstraction, the configuration of screens, capabilities, and contents that traders in financial markets confront corresponds to a global reflex system, or GRS, where $\mathrm{R}$ stands for the reflexively transmitted and reflex-like (instantaneously) projected action- and other capabilities of the system and $G$ stands for the global, scopic view and reach of the reflex system. For the present purpose, which is that of distinguishing between forms of coordination relevant to understanding markets, the term is intended to denote a reflexive form of coordination that is flat (non-hierarchical) in character while at the same time being based on a comprehensive summary view of things - the reflected and projected global context and transaction system. This form of coordination contrasts with network forms of coordination which, according to the present terminology, are pre-reflexive in character - networks are embedded in territorial space, and they do not suggest the existence of reflexive mechanisms of projection that aggregate, recontextualize, and augment the relational activities within new frameworks that are analytically relevant to understanding the continuation of activities. With the notion of a GRS system, I am offering a simplifying term for the constellation of technical, visual, and behavioral components packaged together on financial screens that deliver to participants a global world in which they can participate on a common platform, that of their shared computer screens. On a technological level, the GRS mechanism postulated requires that we must understand as analytically relevant for a conception of financial markets not only electronic connections, but computer terminals and screens - the sorts of teletechnologies (Clough 2000: 3 ) that are conspicuously 
present on trading floors and the focus of participants' attention - as well as the trading floors themselves, where these screens cluster and through which markets pass.

In the following, I begin with an analysis of financial markets as focused upon computer screens as the centerpieces of such a GRS form of coordination. I will also briefly sketch the historical innovation and emergence of the relevant systems in the 1970s and 1980s and point out how they led to a replacement of network markets. In section 3, I address some temporal features of the foreign exchange market which I take as my exemplifying case. A flow architecture, I shall argue, results from a combination of these temporal features with the GRS form of coordination, clustered in time-zone-specific bridgehead centers.

\section{The Mirrored Market: "GRS" Illustrated}

To begin with a concrete case, consider the foreign exchange market, which, with an average daily turnover of 1.2 trillion US dollars in 2001, is the largest financial market and also the most global market (BIS 2001; for comprehensive descriptions of bond-, stockand other financial markets see Abolafia 1996a; 1996b; 1998; Smith 1981; 1990; 1999; Hertz 1998). Unlike other financial markets, the foreign exchange market is not organized mainly in centralized exchanges but derives from inter-dealer transactions in a global banking network of institutions; it is what is called an "over the counter" market. Over the counter transactions are made on the trading floors of major investment and other banks. On the major trading floors of the global banks where we conducted our research ${ }^{3}$ in Zurich and New York, between 200 (Zurich) and $\mathbf{8 0 0}$ (New York) traders were engaged in stock, bond, and currency trading involving various trading techniques and instruments. Smaller floors in Sydney, Zurich, and New York featured between 40 to 80 traders. Up to $20 \%$ of these traders will deal in foreign ex- change at desks grouped together on the floors. The traders on these desks in interbank currency markets are not brokers who mediate deals but rather market makers. They take their own 'positions' in the market in trying to gain from price differences while also offering trades to other market participants, thereby bringing liquidity to the market and sustaining it - if necessary, by trading against their own position. Foreign exchange deals through these channels start in the order of several hundred thousand dollars per transaction, going up to a hundred million dollars and more. The deals are made by investors, speculators, financial managers, central bankers, and others who want to profit from expected currency moves, or who need currencies to help them enter or exit transnational investments (e.g. in mergers and acquisitions). In doing deals, all traders on the floors have a range of technology at their disposal; most conspicuously, the up to five computer screens, which display the market and serve to conduct trading. When traders arrive in the morning they strap themselves to their seats, figuratively speaking, they bring up their screens, and from then on their eyes will be glued to these screens, their visual regard captured by it even when they talk or shout to each other, their bodies and the screen world melting together in what appears to be a total immersion in the action in which they are taking part. The market composes itself in these produced-and-analyzed displays to which traders are attached.

What do the screens show? The central feature of the screens and the centerpiece of the market for traders are the dealing prices displayed on the 'electronic broker' (EBS), a special screen and automated dealing service that sorts orders according to best bids and offers. It displays prices for currency pairs (mainly dollars against other currencies such as the Swiss franc or the euro), deals being possible at these prices. Traders frequently deal through the electronic broker, which has largely replaced the "voice broker" (real life

3 The study is based on ethnographic research conducted from 1997 on on the trading floor of a major global investment bank in Zurich and in several other banks. For a description of this research, see Knorr Cetina/ Bruegger (2002a). See also Bruegger (1999) for an extensive description of currency trading in all its aspects. 
broker); the price action there is also central to the prices they make, as "market makers", for callers approaching them on the "Reuters conversational dealing", another special screen (and computer network) through which they trade. On the Reuters dealing, deals are concluded in and through bilateral "conversations" conducted on screen. These resemble e-mail message exchanges for which the Reuters dealing is also used in and between dealing conversations. On a further screen, traders watch prices contributed by different banks worldwide; these prices are merely indicative, they express interest rather than being dealing prices as such. Traders may also watch their own current position in the market (e.g. their being long or short on particular currencies), the history of deals made over recent periods, and their overall account balances (profits and losses over relevant periods) on this or another workstation at their disposal. Finally, the screens provide headline news, economic commentary, and interpretations which traders watch. An important source of information which also appears on these screens, but is closer to traders' actual dealing in terms of the specificity, speed, and currentness of the information, are internal bulletin boards on which participants input information.

Consider now the installation side of these trading floors. All financial markets today are heavily dependent on electronic information and communication technologies. Some markets, for example the foreign exchange market that is the focus of this work, are entirely electronic markets. As over the counter markets of interbank trading, currency markets rely on electronic technologies that enable the dealer-to-dealer contacts and trading services across borders and continents. Reuters, Bloomberg, and Telerate connections wire together these markets, as do intranets that internally connect the trading room terminals and other facilities of particular banks and groups of banks in global cities. Reuters, Bloomberg, and Telerate are news- and service provider firms. In the year 2001, Reuters had more than 300,000 terminals installed worldwide in all markets and facilities and Bloomberg had more than 150,000 . Revenue from leases of their systems amounted to approximately $\$ 2.5$ billion each at the end of 2001. ${ }^{4}$ With the terminals comes a sophisticated software; dealing and information systems, worksheet, e-mail and customization capabilities, electronic brokerage and accounting services, some of which - like EBS, the electronic broker system - have been developed by the banks themselves. The connections and the intricate and expensive hardware and software delivered by providers and the banking institutions themselves constitute the material infrastructure of financial markets.

How does this bear on the difference between a network form of coordination and the reflexive, global form of coordination discussed in this paper? First, it will be obvious from the description thus far that the material infrastructure of financial markets includes much more than electronic networks, the cable and satellite connections between banks and continents. It includes the installation of trading floors in the global cities that are the financial centers in the three major time zones: London, New York, Tokyo, Zurich, Singapore and a few others (see Sassen 2001: Ch.7; Leyshon/Thrift 1997). The trading floors are the bridgehead centers for a global market that moves from time zone to time zone with the sun. The centerpieces of the interconnected floors are their federations of terminals that feature the sophisticated hardware and software capabilities discussed. When talking about the electronic infrastructure of financial markets, we should not lose sight of the hardware and software of the trading floors themselves and the terminal structures that "ready" these floors for trading. Second, the electronic interconnections which are part of this federation and link all participating institutions, including the service provider firms, are not simply co-extensive with social networks through which transactions flow. As electronic networks they correspond to different construction criteria, involve electronic nodes and linkages 
irrelevant to social relationships, and what flows through them frequently does not derive from social and financial relationships; an example are EBS deals, which are traders' responses to anonymous buying or selling offers provided by an automated electronic broker system. Third and most important, the terminals deliver much more than just windows to physically distant counterparties. In fact, they deliver the reality of financial markets - the referential whole to which "being in the market" refers, the ground on which traders step as they make their moves, the world which they literally share through their shared technologies and systems. The thickly-layered screens laid out in front of traders provide the core of the market and most of the context. They come as close as one can get to delivering a stand-alone world that includes "everything" (see below) for its existence and continuation: at the center the actual dealing prices and incoming trading conversations, in a second circle the indicative prices, account information and some news (depending on the current market story), and further headlines and commentaries providing a third layer of information. It is this delivery of a world assembled and drawn together in ways that make sense and allow navigation and accounting which suggests the globally reflexive character of this form of coordination - and the scopic nature of traders' screens. The dealing and information systems on screen visually "collect" and present the market to all participants.

Two aspects of the system need to be emphasized. One is that the GRS in currency markets assembles not only relevant information about, for example, political events, economic developments, and prices, but "gathers up" the activities themselves - it affords the possibility of performing the market transactions and other interactions through its technological and software capabilities. In other words, the system is reflexive and performative. In fact, it not only affords these possibilities as an option but has drawn market activities in completely. With the exception perhaps of situations where there has been an electronic breakdown, when traders may resort to dealing via the telephone, nearly all dealing transactions - trades of financial instruments - and other interactions are performed on computer screens. This system effectively eliminates the pre-reflexive reality by integrating within its framework all relevant venues of the specialized lifeworld of financial markets. The reality on screen becomes the traders' lifeworld, a lifeworld that is at the same time reflexively transmitted and instantaneously projected. It also offers, beside anonymous venues of trading through the electronic broker, relational dealing systems - e.g. the previously mentioned Reuters conversational dealing, where one trader contacts another and deals with him or her in what natives call a "dealing conversation". This window can also be used for conversing with a financial market friend connected to the system about anything of mutual interest; for example, it is used extensively for soliciting and offering and co-analyzing information. In sum, the global reflex system of financial screens integrates within its framework the conduits for building and maintaining relationships. Should we therefore conclude that this global reflex system is nothing more than an electronic facilitating device for markets that run through networks? Surely not. Roughly $80 \%$ of trades, if not more, according to traders' estimates, are conducted through the electronic broker, which is an anonymous dealing system, as indicated. Even if some of these deals involve parties with whom one entertains a business (or personal) relationship, these relationships remain interactionally irrelevant since the deal-offering parties are not disclosed in advance on the EBS. Among the at most $20 \%$ of the trades conducted through conversational dealing systems, relationship deals are more likely, but they need not be dominant. Any bank accredited for certain dealing limits and electronically connected to the system can approach any other bank through the conversational dealing without a pre-existing or ongoing relationship. Traders also differentiate between "their networks" of contacts, those dealers and clients with whom they interact frequently and consider a subset of the market; their circle of closer "friends" comprising perhaps up to 5 or 10 people with whom they talk almost daily and sometimes extensively 
via the conversational dealing system and the telephone, and the market, which has a large anonymous component. As one trader put it, "(the market on screen) is probably like $99.99999 \%$ anonymous".

The second aspect to be emphasized follows from the description thus far. The mirrored market that is comprehensively projected on computer screens acquires a presence and profile of its own, with its own temporal and other properties. Traders are not simply confronted with a medium of communication through which bilateral transactions are conducted, the sort of thing the telephone stands for. They are confronted with a market that has become a "life form" in its own right, a "greater being", as one of our respondents, a proprietary trader in Zurich, put it - a being that is sometimes coherent but at other times dispersed and fragmented.

LG: You know it's an invisible hand, the market is always right, it's a life form that has being in its own right. You know, in a sort of Gestalt sort of way $(\ldots)$ it has form and meaning.

$\mathrm{KK}$ : It has form and meaning which is independent of you? You can't control it, is that the point?

LG: Right. Exactly, exactly!

KK: Most of the time it's quite dispersed, or does it gel for you?

LG: A-h, that's why I say it has life, it has life in and of itself, you know, sometimes it all comes together, and sometimes it's all just sort of, dispersed, and arbitrary, and random, and directionless and lacking cohesiveness.

$\mathrm{KK}$ : But you see it as a third thing? Or do you mean the other person?

LG: As a greater being.

KK: (...)

LG: No, I don't mean the other person; I mean the being as a whole. And the being is the foreign exchange market - and we are a sum of our parts, or it is a sum of its parts.

The following quote also gives an inclusive definition of the market which brings out its life-like depth. The territorial disputes between economics, sociology, and psychology over market definitions all melt into a sort of "markets are everything" in which the focus can shift from aspect to aspect:

KK: What is the market for you, is it the price action, or is it individual participants, or?

RG: Everything. Everything.

KK: Everything? The information?

RG: Everything. Everything. How loudly he's screaming, how excited he gets, who's selling, who's buying, where, which centre, what central banks are doing, what the large funds are doing, what the press is saying, what's happening to the CDU [a political party in Germany], what the Malaysian prime minister is saying, it's everything everything all the time.

Who the buyers and sellers are, what significant actors and observers both in the market and outside it do and say, all the agents, activities, and contextual events indicated in this quote and the reactions of market observers and participants to these events represent the market. The quote comes from an experienced trader who had worked in several countries, including ones in the Far East, before coming to Zurich. Note that his "the market is everything" refers to the manifold things that one finds on financial screens, the news and news commentary, the confidential information about what some major players are doing, and the prices. The screens, or perhaps we should say the availability of a projection plane for financial markets, appear to have enlarged rather than reduced the world of this market. It has undeniably enlarged the world beyond that which ordinarily flows through trading networks, which, as we shall see in the next section, historically was to a large extent price information.

The notion of a network draws on a powerful convergence of organizational changes, technological developments, and broader cultural transformations of values which sustain the network not only as an analytic concept for the investigation of social structure, but also as a model and advertisement for how things in many areas should be structured. The most important convergent development that has contributed to the recent renaissance of network concepts is surely that of information and communica- 
tion technologies which are based on electronic linkages between geographic areas and are referred to in terms of a vocabulary of nets, webs, circuits, and nodes. Information and communication technologies have made the network notion salient, strengthened pre-existing trends toward network forms of organization, and facilitated some of these developments. Castells accordingly writes of the network society where "flows of messages and images between networks constitute the basic thread of our social structure" (Castells 1996: 476-477; compare Lash 2002). He sees dominant societal functions organized in global information technology networks linked by these communications, while subordinate functions fragment in local settings where people occupied with these functions become increasingly segregated and disconnected from each other. But the central question for social scientists is how these technologies are instantiated in concrete areas of practice, and here a different picture emerges. From the traders' perspective, and from the perspective of the observer of traders' lifeworld, the dominant element in the installation of trading floors in globally interconnected financial institutions is not the electronic infrastructural connections - the "pipes" (Podolny 2001: 33) or arteries through which transactions flow - but the computer screens and the dealing and information capabilities which instantly reflect, project, and extend the reality of these markets in toto. They give rise to a form of coordination that includes networks but also vastly transcends them, projecting an aggregate and contextualized market. The screens on which the market is present are identically replicated in all institutions and on all trading floors, forming, as it were, one huge compound mirroring and transaction device to which many contribute and on which all draw. As an omnipresent complex "Other", the market on screen, takes on a presence and profile in its own right with its own self-assembling and selfintegrating features (for example, the best prices world-wide are selected and displayed), its own calculating routines (for example, accounts are maintained and prices may be calculated), and self-historicizing properties (for example, price histories are displayed and a multiplicity of other histories can be called up). The electronic programs and circuits which underlie this screen world assemble and implement on one platform the previously dispersed activities of different agents; of brokers and bookkeepers, of market-makers (traders) and analysts, of researchers and news agents. In this sense, the screen is a building site on which a whole economic and epistemological world is erected. It is not simply a "medium" for the transmission of pre-reflexive interactions.

\section{How Did the Market Get on Screen? The Move Away from Network Markets}

The market has of course not always been on screen. The history of foreign exchange markets since the 1970s instantiates and exemplifies for other areas the transition from a network market to a flow market utilizing a central, compound space. Let us start with the breakdown of the Bretton Woods Agreement, which had hitherto effectively fixed exchange rates. In the 1970 s, first the USA (1971), then major European countries, including Britain by 1979, and finally Japan in the early 1980s, abolished exchange controls, effectively eliminating the Bretton Woods Agreement of fixed exchange rates in place since 1944 and allowing foreign exchange trading for purposes of speculation. Before the breakdown, foreign exchange markets also existed: foreign exchange deals are cross-border exchanges of currencies. Such exchanges were born with the dawn of international trade and persisted through all ages. But in the 30 years of the Bretton Woods Agreement, foreign exchange deals reflected by and large the real requirements of companies and others that needed foreign exchange to settle bills and pay for goods. When exchange controls were removed, currency trading itself became possible as a market where exchange reflected price movement anticipation. In 1986 the dealing rooms of the world had taken off, with an average of US $\$ 150$ billion and as much as $\$ 250$ billion being traded around the globe, double the volume of five years before (Hamilton/Big- 
gart 1993). In April 1998, according to the Bank of International Settlement's Triennial Survey, the average daily turnover in traditional global foreign exchange instruments had risen from $\$ 36.4$ billion in 1974 to $\$ 1.5$ trillion (BIS 1998). Two-thirds of this volume derives from "over the counter transactions", i.e. from inter-dealer transactions in a global banking network of institutions. Banks had responded quickly to the business opportunities which arose with the freedom of capital that the breakdown of the Bretton Woods system initiated. They also responded to an increasing demand stimulated by volatile exchange and interest rates reflecting various crises (e.g. the energy crisis of 1974) and to the tremendous growth in pension fund and other institutional holdings that needed to be invested. Though the volume of trading has since receded to approximately $\$ 1.2$ trillion with the economic downturn and the elimination of some currencies according to the latest BIS survey (2001), the foreign exchange market is still by far the largest market in daily turnover worldwide.

When exchange controls were removed in 1971, the current foreign exchange market was born. Traders, however, had no computers and trading was a question of finding and negotiating this market, which lay hidden within geographical space. A trading room, in the early beginnings, was a room with desks and phone lines and a calculating machine. It may also have had a central phone booth installed in the middle of the room, originally serving as a quiet place to take international phone calls which, early on, still had to be ordered through the phone company; only national calls could be dialed directly. A most important device was the "ticker", a device which churned out " 50 meters a day" of news headlines and price pointers, as a former participant put it (see Preda 2003 for its specific history). Activities on the floor centered around "finding the market", that is finding out what the price of a currency was and who wanted to deal. In the following quote, a former chief of trading recalls how he continually chased after the market:

P: (...) So you had to constantly find out what the rates were in countries.
KK: And you did this by calling up banks? P: By, yes. And there were also calls on the telex by other banks who either wanted to trade or wanted to know, simply wanted to know where dollar-Swiss was.

KK: (...)

P: Yes, you were a broker for traders, every morning you had to fetch all the prices in Europe, Danish crowns, Swedish crowns, Norwegian crowns, and such, national currencies every morning, the opening rates. You gave them to traders, they calculated them in Swiss francs, and wrote them down on big sheets.

B: And you offered two-way prices already? P: (...) In Swiss banks exchange rates were determined by negotiation, like in a bazaar (etc.).

The notion apresentation, a term adapted from Schutz and Luckmann (1973: 11), refers to the transport of details from different geographical locations and time zones to a particular domain of activities. A partial attempt at apresenting markets occurred before the introduction of screens: the prices written down by hand on the "big sheets" to which P. refers in the above quote were displayed on wall boards and can be seen as early attempts at market apresentation. When screens appeared, they were at first no more than substitutes for the "big sheets": displays on which the handwritten price sheets put together by female clerks were projected on the basis of pictures taken of the sheets on the floor. This form of apresentation rested upon a chain of activities that was in important respects indistinguishable from the one that fetched prices in pre-screen times: it involved narrowing down where the market was by calling up or telexing banks, writing down the responses by hand (and perhaps recalculating prices in national currencies), and making this information available for internal purposes through a form of central presentation. Screens began to apresent a dispersed and dissociated matrix of interests more directly only in 1973, when the British news provider Reuters first launched the computerized foreign exchange system 'Monitor', which became the basis for this electronic market (Read 1992). Monitor still 
apresented the market only partially, however, since it, too, only provided indicative prices. Nonetheless it did, from the beginning, include news. Actual dealing remained extraneous to screen activities and was conducted over the phone and telex until 1981, when a new system, also developed by Reuters that included dealing services, went live to 145 institutional customers in nine countries. The system was extended within a year to Hong Kong, Singapore, and the Middle East, resulting in a market with a world-wide presence (Read 1992: 283ff., 310-311). From that point onward, deals could be concluded on screen within two to four seconds, and dealers could communicate via the screen. Yet even before this system went live, the first system, Monitor, from its launch onward, radically changed one aspect of dealing: it answered the question of where the market was, i.e. what the prices of currencies were and who might be ready to deal.

Before the market-on-screen, prices differed from place to place and had to be ascertained afresh for every deal through long and painful processes of phoning up banks and waiting for lines from operators for overseas calls. After the introduction of Monitor, prices suddenly became available globally to everyone connected by the system, in a market that functioned between countries and between continents. Before the market-onscreen, there were dispersed networks of trading parties entertaining business relationships. After the introduction of the computerized screen quotes in 1981, "the market" no longer resided in a network of many places, but only in one, the screen, which could be represented identically in all places. The economic counterpart to this coming together of all market fragments in one location was the declining importance of arbitrage. Price differences between locations made visible on screen, even if they involve only indicative prices, will quickly be eliminated, as the information about them is available to all traders connected and traders try to take advantage of these differences. The sociological counterpart to Monitor and its expansion into dealing services and the many capabilities and information windows the successor systems provide is the emergence of GRS as a mechanism of coordination. Not only were markets recast with the coming together and expansion of all their functions and contexts on financial screens, but forms of social coordination were also reconfigured.

\section{The Market as a Moving Timeworld and the Flow Architecture of this Timeworld}

I now want to address the flow architecture of foreign exchange markets which has been made possible by the GRS. The notion of a flow, as I shall use the term, responds to the aggregate properties the market acquired after being put on screens and to the global processual qualities of this market. To start things off, consider the continuation of the conversation reported before with the proprietary trader who defined the market on screen as a life form. He also pointed to the continuously changing shape of the market:

KK: I want to come back to the market, what the market is for you. Does it have a particular shape?

LG: No, it changes "shape" all the time.

Traders perform their activities in a moving field constituted by changing dealing prices, shifting trading interests (the indicative prices), scrolling records of the immediate past that are continually updated, incoming conversational requests, newly projected market trends, and emerging and disappearing headline news, commentaries and economic analyses. In other words, they perform their activities in a temporal world; the market itself is intrinsically dynamic and processual and the global reflex system of financial screens displays, enhances and accelerates the market process and its dynamic properties. As the information scrolls down the screens and is replaced by new information, a new market reality continually projects itself. The constantly emerging lines of text at times repeat the disappearing ones, but they also add to them and replace them, updating the reality in which traders move. The market as a "greater being", as an empirical object of ongoing activities and effects, continually transforms itself like a bird changing direction in mid-flight, creating 
the anticipation problem traders confront. From one point of view, a defining characteristic of a financial market is its non-identity with itself. Markets are always in the process of being materially defined, they continually acquire new properties and change the ones they have. It is this ontological liquidity of financial markets that contributes to their perception as a reality in flux. The flow of the market reflects the corresponding stream of activities and things: a dispersed mass of market participants continues to act, events continue to occur, policies take hold and have effects. Markets are objects of observation and analysis because they change continually; and while they are clearly defined in terms of prices, news, relevant economic indicators, and so on at any given moment, they are ill-defined with respect to the direction they will take at the next moment and in the less immediate future.

Historically, markets were marketplaces, physical locations where buyers and sellers were able to meet and coordinate their interests (e.g. Agnew 1986: 18). Likewise, our concepts of an everyday reality tend to be spatial concepts. We see reality as an environment that exists independently of us and in which we dwell and perform our activities. The very notions of a lifeworld and of a world on screen as used so far in this paper also suggest spatiality; they suggest that the idea of a spatial environment can be extended to electronic domains as these become - for some of us - a place to work and live. The problem with these notions in regard to time is that they imply that time is something that passes in these spatial environments but is extraneous to the environment itself. We relate the existence of a lifeworld, of an environment, or of everyday reality more to the physical materiality of a spatial world than to any temporal dimension. We also express, one assumes, the durability of the physical world compared with the human lifespan through spatializing concepts. The point is that the screen reality discussed has none of this durability. It is more like a carpet of which small sections are rolled out in front of us. The carpet grounds experience; we can step on it, and change our positioning on it. But this car- pet only composes itself as it is rolled out; the spatial illusions it affords hide the intrinsic temporality of the fact that its threads (the lines of text appearing on screen) are woven into the carpet only as we step on it and unravel again behind our back (the lines are updated and disappear). Thus the screen reality - the carpet - is a process, but it is not simply like a river that flows in the sense of an identical mass of water transferring itself from one location to another. Rather, it is processual in the sense of an infinite succession of non-identical matter projecting itself forward as changing screen. This is what one may call the flowcharacter of this reality.

This formulation suggests that what I have called the global reflex system - and particularly its screen component - is necessary for this flow reality to emerge: it is through the performative and presentational capabilities of the GRS mechanism and its information feeds that the market acquires the properties of an aggregate entity and, while being performed and reflexively analyzed and projected, takes on the character of a stream of things moving forward as a whole. We also need to distinguish here between participating financial flows and the composite reality of a flowing market. Traders sometime contrast "taking a view" of a market development, which is subjective, with having concrete information about what they call "orders" and "flows", which is objective, since orders and flows are constitutive components of financial markets. Financial orders refer to requests for trades once the price of a financial instrument reaches a certain level; when an order is executed, it becomes a flow. Financial flows refer to volumes of a financial instrument changing positions and accounts; in accounting terms, flows are distinguished from "non-changing" objects in that they must be expressed in terms of a time interval (Houthakker/Williamson 1996: 9). In foreign exchange, large flows are large amounts of currencies being bought or sold. The sales may arise from mergers and acquisitions of firms that require large cross-border payments, from central bank transactions in support of a particular currency, etc. Advance and concurrent knowledge of large orders and flows is important to traders be- 
cause these orders and flows may "move the market" - they may change price levels. They may also potentially set in motion new market trends and reverse upward or downward tendencies in currency prices. To participants, orders and flows are part of the market as an independent reality and they are at the same time forces that drive the market.

Participants' understandings of flows can be related to common notions of flow which we should briefly consider. Social scientists tend to associate the term flow either directly with (1) things traveling or (2) with fluidity. The first idea responds to the increased mobilities of contemporary life (Urry 2000: 15$16,36-37)$. It gives expression to the phenomenon that it is not only people that commute, travel, and migrate in seemingly ever-increasing numbers, but that messages and information also move. It is particularly the traveling of communications that underpins the idea of a network society as one based on flows of information (e.g. Castells 1996). This idea is important, but it does not quite capture what happens in the case of financial flows. In currency trading, financial flows refer to payments that imply adjustments of accounts. No physical transfers of money need take place for this purpose; what flows in the sense of something being transferred is financial (market-, payment-, etc.) power as an abstract capacity rather than actual money. The payments are important to market participants because they influence price levels, as indicated. The changes that occur and concern participants in response to financial flows pertain to the market as centrally composed of price levels. Also changing in conjunction with large financial flows may be market stories, commentaries, and analyses, headline news, trend extrapolations, and the like - all belonging to the level of the market as presented on screen. This level of the market is what the notion of a flow market as used in this paper targets.

The second meaning of flow found in the literature is that of fluidity; it draws on the distinction between liquids and solids. For example, analysts who emphasize fluidity conceptualize the current stage of modernity as marked by a transition from more solid forms of order and tradition to structures that are more liquid and fluid, or that are melting, as in Marx's famous phrase that "all that is solid melts into air" (e.g. Berman 1982; Bauman 2000). The liberalization of traditional education exemplifies this trend, as does the deregulation of markets, the flexibilization of labor and the breakdown and replacement of traditional family relations (e.g. Lasch 1978). This idea of the "melting of the solid" comes closer to the one used here, but the point about the screen reality as a flow is not that it is nomadic (without itinerary) and unmarked by the traces of social and economic structure. The point is the projection and reconstitution of this reality as one that is continually emerging in a piecemeal fashion. One can compare it to a text that is in the process of being written simultaneously by many authors, that is composed in the process of writing out numerous different components, and that reaches no further than the contributor's pen. It is the emergence of this market text in episodic pieces, contemporaneously with the agent's activity and the short duration of the text, that the notion of a flow as used here is intended to capture. I also suggest that it is possible to retain notions such as that of a world while remaining a ware of the scrolling change of this particular world. The screen that rolls out the lifeworld in which traders move nonetheless presents such a lifeworld; it presents a complex environment composed of "walkable" regions and horizons that ground activities. The ground may be shifting continually and the lifeworld is "in flight". But traders are able to deal with this flux; their ways of "inhabiting" it are adapted to the timeworld they confront. An example of this adaptation is the traders' tendency to keep pace with their world-in-flight by following market movements in their trading, and by developing a "feeling" for these movements. Traders also analyze the short-term and long-term tendencies of their lifeworld's movements in terms of stories and "big pictures" that give duration to particular states.

If markets are continually changing processes with variable time attributes they can also be viewed as time contexts that move across space, or to be precise, across time zones. Here the global character of financial 
markets, particularly of currency markets, becomes important. One can see these markets as moving in and out of time zones continually with the sun, and as they do, of taking on different features and updating their positions. As global entities, markets have their own instrument- and clock-related characteristics that characterize them in the aggregate. For example, markets have characteristic "speeds" indicated by the price movements which are at the center a changing market process. In currency spot trading, which is the direct exchange of currencies, prices tend to change within split seconds during periods of average activity. As a consequence, the currency trading timeworld moves forward at a breath-taking pace. Another attribute is the liquidity of a market, which in this context indicates the speed with which a financial instrument can be bought or sold, without significant price changes. Markets will be "thin" (have few participants willing to trade) at certain times and "deep" at others, with market liquidity varying over time. Markets also undergo seasonal variations, for example, periods of low trading volume during the holiday season in December, when the accounting end of the year draws close. When markets are conceived as moving across time zones, additional features become relevant, underscoring their character as moving entities and timeworlds. To make this character plausible, I want to consider the following aspects of global markets, focussing again on the foreign exchange market as the most developed global market. A first set of characteristics refers to the temporal unity of these markets: they keep their own clock and times and they have their own global schedules and calendars. A second characteristic of these markets is that they are globally "exclusive" systems that have left behind their natural embeddedness in local and physical settings. This point will allow me to address the architecture of these markets as based on bridgehead centers in the three major time zones. My final point illustrates the working of a flow architecture as one where such centers play "bridging" and mediating roles in giving support to a moving market and in updating and forwarding the market on a time zone trajectory.
A first feature that ties into the view of global foreign exchange markets as moving time contexts is that they follow their own time, which is Greenwich Mean Time (GMT). Greenwich Mean Time, the time and date of the zero meridian which runs through Greenwich, England was adopted as a universal standard in November 1884 during the meeting of the International Meridian Conference in Washington, DC, USA. This conference drew up an international date line and created 24 time zones. Prior to that, the United States alone had over 300 local times (see Zerubia vel 1982: 12-13 for its interesting historical origin). Since these markets have no central location, time is fixed to a particular coordinate of the globe to assure global identification of the correct transaction date. If this were not the case, a transaction in New York requiring delivery in Sydney two days later and the receiving side in Sydney might not register the same delivery date. But this also means that the respective markets carry their own time reckoning with them. As an aggregate of positions, orders, flows, and traveling "books" (accounts), they remain independent of local time zones. A further aspect of the temporality of global markets is "calendars" and schedules: dates and hours set for important economic announcements and for the release of periodically calculated economic indicators and data. These calendars and schedules structure and pace participants' awareness and anticipation. They originate in a particular world region and the respective time zones; for example, the data might be released in the US at Eastern standard time and they will consist of national statistics referring, for example, to the US, or of aggregate statistics referring to a group of nations, as with European Union data. But calendars and schedules from all three major time zones are relevant and will be listed in daily and weekly market "schedules". These schedules "anchor" market developments in national or regional economies' fundamental characteristics. Yet as transnationally relevant collections of time points that punctuate and dramatize the ordinary temporal flow of market events and observations, they also belong to the disembedded timeworld of global markets. 
This disembedding is the second feature 1 want to discuss. It too sustains the notion of global markets as moving timeworlds. Giddens uses the notion of disembedding to refer to the "lifting out of social relations from local contexts" (Giddens 1990: 21-29). I use the term to refer to the phenomenon that the markets observed appear removed from their local context in terms of participants' orientation, their inherent connectivity and integration as the key to overcoming the geographical separation between participants, their rules of trading practices, their forms of compensation, and the like (see Knorr Cetina/ Bruegger 2002a for an overview of these characteristics). To give some examples, market participants (e.g. traders) are disembedded in the sense that they are oriented towards one another across time zones rather than toward the local environment. They remain oriented to the translocal environment even after their working hours, continuing to watch the market that has moved on to another time zone through hand-held Reuters' instruments and TV-channels. An important feature that points beyond this global orientation is what has been called elsewhere the reciprocal interlocking of time dimensions among traders as a means for achieving a level of intersubjectivity in global fields. What holds participants together across space is a "community of time" rather than a community of space, as in traditional societies. This community of time comes about, for example, by market participants on dispersed trading floors watching the market virtually continuously in synchronicity and immediacy for the duration of their working (and waking) hours. ${ }^{5}$ All three aspects are important here: synchronicity refers to the phenomenon that traders and salespeople observe the same market events simultaneously over the same time period; continuity means they observe the market virtually without interruption, having lunch at their desks and asking others to watch when they step out; and temporal immediacy refers to the immediate real time availability of market transactions and information to participants within the appropriate institutional trading networks. Traders may also see themselves as belonging to global professional communities and they exhibit similar lifestyles across continents. Another disembedding feature are the rules of trading practice which are not covered by national law but correspond to a lex mercatoria (a rule of trading practices) holding among participants on a global level, and reinforced in trading interactions without recourse to formal law.

Going beyond disembeddedness and asking what "supports" a market that moves freely across time zones, one can point to the trading floors in global cities where the moving market resides during time zone hours, becomes further articulated and defined, and then moves on to the next time zone. To begin, let me draw a distinction between a globally inclusive and a globally exclusive cultural form. A globally inclusive financial marketplace would be one where individual investors in any country are able to trade assets freely across national boundaries. Such a system requires, among other things, the computer penetration of investor locations (e.g. households), language capabilities or unification, Web architectures, payment and clearing arrangements between exchanges, regulatory approvals, and national pension and insurance systems that support individual financial planning. Such systems are in the process of being created in some regions, but they are far from being in place on a world wide basis. On the other hand, in the area of institutional trading considered in this paper, a global market of a different kind

5 As Harvey has argued (1989: 239-259), increasing time-compression is a characteristic of the whole process of modernity and of post-industrialization. A similar argument had been advanced by McLuhan (1964: 358), who proposed that electricity establishes a global network of communication that enables us to apprehend and experience media-transmitted events nearly simultaneously, as in a common central nervous system. To date, however, few media events are "simultaneously" transmitted across time zones, and media content is adapted to local cultures and locally reinterpreted. We argue that many other mechanisms and infrastructures and in fact a secondary economy of information collection and transmission need to be in place to create a global social form. 
has been in evidence for some time. This form of globality is not based upon the penetration of countries or of individual behavior. Instead, it rests on the establishment of bridgehead centers of institutional trading in the financial hubs of the three major time zones: in New York, London, Tokyo, and Zurich, Frankfurt or Singapore. The moving market "rests" in these bridgehead centers where it becomes articulated and revised. The bridgehead centers contribute to the markets' continuation by the trading activities of their "market makers" (the traders who take their own positions in the market), the activities of their salespersons, and others. These activities support the market, which becomes anchored in the time-zone-specific global reflex systems of trading floors. The activities also change the market, and this contributes to the notion of the market as a flow in the sense introduced before, and as a moving timeworld. Participants coming to work in New York in the morning will not be confronted with the same market they left at the end of their previous working day. They will see an updated version of this market, one that bears the mark of the events happening in the intermediate time zones of Asia and Europe. In addition, these markets will arrive "whole", at every new time zone and take off "whole" to the next one. This is somewhat simplified, but let us see what one might mean by such a statement. When traders arrive at their desks in the morning in Tokyo and open their screens they will find summary accounts of what happened before in the New York time zone - these accounts are encapsulated in closing rates, index values, volume statistics, intraday trading trends, etc. They will also find more qualitative summaries relayed to them by their contacts in the earlier time zone in their conversational dealing screens. In addition, traders themselves will make efforts to find out more about market developments in the earlier time zone by listening to relevant news services at home, calling friends, or contacting them via the conversational dealing system before and while they begin dealing. Most major institutional trading floors also have morning meetings where such information is reported, analysts ${ }^{\prime}$ summaries prepared in another time zone are transmitted over intercoms, and onfloor analysts and economists relate their assessment of the situation. Similarly, at Tokyo closing time, traders and analysts in this time zone will transmit summary information to contacts, bulletin boards, and other outlets in the next (European) time zone and they may be contacted by those working there via phone or electronic mail for specific and concrete information. The European (London, Zurich, Frankfurt) and American (New York) time zones overlap by several hours (New York institutional trading starts at 8 am, which is 2 pm Central European Time). In response to the overlap between the European and North American opening hours, the markets will not "move on" immediately but will trade simultaneously until Europe closes the markets tend to get "hectic" at these times just as they will be "silent" when Tokyo is not yet very active and New York has closed. When the European closing time approaches, the same sort of summarizing and forwarding described earlier will take place. The overlap between Europe and the US corresponds to a "time gap" between the US (New York) and Japan (Tokyo) provoked by the larger time difference between these cities where no or little trading takes place in both time zones. Traders in the same institution, dealing in the same instrument (say currency options), may cooperate across time zones when longer-term contracts are involved (e.g. options) and positions cannot be closed at the end of a trading day. In this case, the market's move to the next time zone may involve the transfer of a "global book" - an electronic record of all contracts entered, including those added and structured in the forwarding time zone. Global books incorporate particular philosophies of trading whose content and adaptation to time-zone-specific circumstances will be discussed in similar beginning- and end-of-day global conversations between traders in different zones.

\section{Conclusion}

The market "flow" refers to these forwarded features as well as the aggregate positions and accounts that circle the globe while changing continuously with activities and events. A flow "architecture" refers to the 
support systems of these flows, which I take to be the time-zone-specific trading floor settings with their global reflex systems. The global reflex systems provide for the market's unity and movement across space. They also suggest a form of coordination of global fields that is to be distinguished from spatially embedded network structures. As the above examples show, the market's movement across the globe has an accomplished sense; it cannot be detached from the activities of market participants who sustain the

\section{References}

\begin{abstract}
Abolafia, Mitchel (1996a): Making Markets: Opportunism and Restraint on Wall Street. Cambridge, MA: Harvard University Press.
\end{abstract}

Abolafia, Mitchel (1996b): "Hyper-Rational Gaming", in Journal of Contemporary Ethnology, 25, 2, 226-250.

Abolafia, Mitchel (1998): "Markets as Cultures: An Ethnographic Approach", pp 69-85 in Michael CalIon (ed.), The Laws of the Markets. Oxford: Blackwell. Agnew, Jean-Christ (1986): Worlds Apart. The Market and the Theatre in Anglo-American Thought, 15501750. Cambridge: Cambridge University Press.

Baker, Wayne E. (1981): Markets as Networks: A Multimethod Study of Trading Networks in a Securities Market. PhD Dissertation.

Baker, Wayne E. (1984): " The Social Structure of a National Securities Market ${ }^{\prime \prime}$, in American Joumal of Sociology, 89, 4, 775-811.

Baker, Wayne E./ Robert R. Faulkner/Gene A. Fisher (1998): "Hazards of the Market: The Continuity and Dissolution of Interorganizational Market Relationships", in American Sociological Review, 63, 147-177.

Bank for International Settlements (1998): Triennial Central Bank Survey of Foreign Exchange and Derivatives Market Activity in April 1998: Preliminary Global Data. Basle: BIS.

Bank for International Settlements (2001): Triennial Central Bank Survey of Foreign Exchange and Derivatives Market Activity in March 2001 - Final Results. Preliminary Global Data. Basle: BIS.

Baumann, Zygmunt (2000): Liquid Modemity. Cambridge: Polity Press.

Berman, Marshall (1982): All That is Solid Melts Into Air: The Experience of Modernity. London: Verso. market in a particular time zone and then "compute" and discursively summarize a market's features over time zone intervals as they forward these features to the next time zone. By the same token, participants provide for the continuation of global markets, but their activities are not the focus of this paper. Also left unconsidered, given the limits of this paper, are the activities of the information and service provider firms that develop and service the global reflex systems and assume much of the apresentation function.

Barringer, Felicity (2002): "Bloomberg, Without Bloomberg, Faces an Industry in Retreat", in New York Times, Sunday September 2, BU 5.

Bruegger, Urs (1999): Wie handeln Devisenhändler? Eine ethnographische Studie über Akteure in einem globalen Markt. Universität St. Gallen: Dissertation.

Burt, Ronald (1983): Corporate Profits and Cooperation: Networks of Market Constraints and Directorate Ties in the American Economy. New York: Academic Press.

Burt, Ronald (1992): Structural Holes: The Social Structure of Competition. Cambridge, MA: Harvard University Press.

Castells, Manuel (1996): The Rise of the Network Society. New York: Harper \& Row.

Clough, Patricia (2000): Autoaffection. Unconscious Thought in the Age of Teletechnology. Minneapolis: University of Minnesota Press.

DiMaggio, Paul/Hugh Louch (1998): "Socially Embedded Consumer Transactions: For What Sorts of Purchases do People Use Networks Most " $^{\prime \prime}$ in American Sociological Review, 63, 5, 619. 637.

Fligstein, Neil (1996): "Markets as Politics. A Political-Cultural Approach to Market Institutions", in American Sociological Review, 61, 4, 656-673.

Fligstein, Neil (2001): The Architecture of Markets an Economic Sociology of $21^{\text {st }}$ Century Capitalist Societies. Princeton: Princeton University Press.

Giddens, Anthony (1990): The Consequences of Modernity. Stanford: Stanford University Press.

Granovetter, Mark (1985): "Economic Action and Social Structure: The Problem of Embeddedness", in American Joumal of Sociology, 9, 481-510. 
Hamilton, Gary C./Nicole W. Biggart (1993): "Market, Culture and Authority: A Comparative Analysis of Management and Organization in the Far East", pp. 181-221 in Mark Granovetter/Richard Swedberg (eds.), The Sociology of Economic Life. Boulder, CO: Westview Press.

Harvey, David (1989): The Condition of Postmodernity. Cambridge: Blackwell.

Hertz, Ellen (1998): The Trading Crowd. An Ethnography of the Shanghai Stock Market. Cambridge, England: Cambridge Lniversity Press.

Houthakker, Hendrik/Peter Williamson (1996): The Economics of Financial Markets. New York: Oxford University Press.

Knorr Cetina, Karin/Urs Bruegger (2002a): "Global Microstructures: The Virtual Societies of Financial Markets", in American Joumal of Sociology, 107, 4, 905-950.

Knorr Cetina, Karin/Urs Bruegger (2002b): "Traders' Engagement with Markets: A Postsocial Relationship", in Theory, Culture \& Society, 19, 5/6, 161185.

Lasch, Christopher (1978): The Culture of Narcissism. New York: W.W. Norton.

Lash, Scott (2002): Critique of Information. London: Sage.

Leyshon, Andrew/Nigel Thrift (1997): Money Space: Geographies of Monetary Transformation. London: Routledge.

McLuhan, Marshall (1964): Understanding Media. London: Routledge.

Podolny, Joel (2001): "Networks as the Pipes and Prisms of the Market", in American Joumal of Sociology, 107, 1, 33-60.

Preda, Alex (2003): "Of Ticks and Tapes: Financial Knowledge and Price-Recording Technologies in $19^{\text {th }}$ Century Financial Markets", in American Journal of Sociology (forthcoming).

Read, Donald (1992): The Power of News. The History of Reuters. Oxford: Oxford University Press.

Sassen, Saskia (2001): The Global City, $2^{\text {nd }}$ ed. Princeton, NJ: Princeton University Press.
Schutz, Alfred/Thomas Luckmann (1973): The Structures of the Life-World. Evanston, ILL: Nortwestern University Press.

Smith, Charles W. (1981): The Mind of the Market. A Study of the Stock Market. New Jersey: Rowman \& Littlefield.

Smith, Charles W. (1990): Auctions. The Social Construction of Value. Berkeley; University of California Press.

Smith, Charles W. (1999): Success and Survival on Wall Street: Understanding the Mind of the Market. New York: Rowman \& Littlefield.

Swedberg. Richard (1994): "Markets as Social Structures", pp. 255-282 in Neil Smelser/Richard Swedberg (eds.), The Handbook of Economic Sociology. Princeton: Princeton University Press.

Swedberg. Richard (1997): "New Economic Sociology. What has been Accomplished? What is Ahead?", in Acta Sociologica, 40, 161-182.

Swedberg, Richard/Mark Granovetter (1992): "Introduction", pp. 1-26 in The Sociology of Economic Life. Boulder: Westview Press.

Urry, John (2000): Sociology Beyond Societies. Mobilities for the Twenty-First Century. London: Routledge. Uzzi, Brian (1997); "Social Structure and Competition in Interfirm Networks: The Paradox of Embeddedness", in American Science Quarterly, 42, 1, 35-67.

Uzzi, Brian (1999): "Embeddedness in the Making of Financial Capital: How Social Relations and Networks Benefit Firms Seeking Financing", in American Sociological Review, 64, 481-505.

White, Harrison (1981): "Where do Markets Come From?", in American Joumal of Sociology, 81, 3, 517-547. White, Harrison (1993): Markets as Production Networks. New York: Russel Sage Foundation.

White, Hartison (2002): Markets from Networks. Socioeconomic Models of Production. Princeton: Princeton University Press.

Zerubiavel, Eviatar (1982): "The Standardization of Time: A Sociohistorical Perspective", in American Journal of Sociology, 88, 1, 1-23.

Karin Knorr Cetina is Professor of Sociology at the University of Konstanz, and member of the Institute for Global Society Studies, University of Bielefeld, Germany. She is a former president of the International Society for Social Studies of Science, a former member of the Institute for Advanced Study, Princeton, and a future member of the Center for Advanced Study in the Behavioral Sciences in Palo Alto, CA. She has published many articles in international journals on 
knowledge, science and financial markets and is the author of several books, including Epistemic Cultures: How the Sciences Make Knowledge (Harvard University Press, 1999), which received two international prizes. She is currently working on a book on the Global Microstructures of Financial Markets.

\author{
Karin Knorr Cetina \\ Department of Sociology \\ University of Konstanz \\ Box D-46 \\ 78457 Konstanz \\ Germany \\ karin.knorr@uni-konstanz.de
}

